\title{
Obituary
}

\section{Dr Vikram A. Sarabhai}

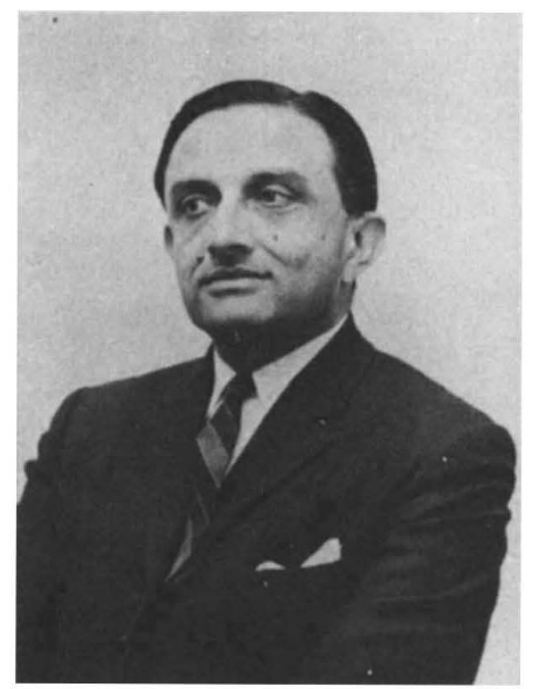

IN the early hours of December 30, 1971, Dr Vikram Ambalal Sarabhai, chairman of India's Atomic Energy Commission, died unexpectedly of a heart attack at Trivandram in South India. He was 52 years old.

Dr Sarabhai was a well known scientist working in the area of cosmic rays, particularly in the use of the cosmic-ray signal for the study of interplanetary phenomena. At the time of his death, besides being chairman of the AEC he was also director of the Physical Research Laboratory, Ahmedabad, chairman of the Indian Space Research Organization and director of the Space Science Technology Centre at Thumba.

Dr Sarabhai was born on August 12, 1919. His early education was at Ahmedabad, but later he went to Cambridge and took his Tripos in Natural Sciences in 1939 at St John's College. $\mathrm{He}$ started his professional career at the Indian Institute of Science, Bangalore, with Professor Sir C. V. Raman. There he wrote his first paper on testing the randomness of the arrival time distribution of cosmic-ray particles. After the war he returned to Cambridge to work for his $\mathrm{PhD}$, which he received in 1947. Soon after his return he founded the Physical Research Laboratory at Ahmedabad. Most of his later scientific work was done at this laboratory, where he built up excellent schools of cosmicray physics, space science, upper atmosphere and ionosphere physics, theor- etical nuclear physics and plasma physics.

In the field of cosmic-ray variations, along with a number of his colleagues, he made several significant contributions. He was one of the first people to realize, through experiment, that the variations of the muon component could not be understood only in terms of atmospheric effects but, in fact, implied an anisotropy of cosmic rays in interplanetary space. He pointed out that by working at near-equatorial stations his measurements would be particularly sensitive to the anisotropy of cosmic rays in the plane of the ecliptic. His work showed that this anisotropy changed with the 11-year cycle of solar activity.

The special object of the work of Dr Sarabhai and his collaborators at Ahmedabad was to identify the electromagnetic conditions in interplanetary space with measurements of cosmic-ray intensity and disturbances in the geomagnetic field made on the surface of the Earth. In 1963 Dr Sarabhai suggested that the variation in the intensity of the green coronal emission line implied a variation in the velocity of the solar wind emitted from different regions of the Sun. He was also probably the first to describe the interesting interplanetary and geomagnetic phenomena resulting from special electromagnetic configurations produced by the interplay of fast and slow streams of plasma emanating from the Sun. On the assumption that periodic fluctuations in the horizontal component of the Earth's magnetic field are due to the large scale magnetic field inhomogeneities in the solar plasma impinging on the magnetosphere and by analysing the period of these fluctuations, he and his collaborators suggested that the average scale size of these inhomogeneities is 0.02 a.u.

Using large counting rate telescopes, some of them pointing north, he initiated a study of interplanetary conditions not only in the plane of the ecliptic but also at high heliolatitudes. Later he and Dhanju set up a very large counting rate muon telescope at Chacaltaya to study fluctuations in the dynamical range 1 to 30 cycles $^{-1}$, and they were able to show that there is a complete correspondence between the peaks in the frequency spectrum of the cosmicray fluctuations and that of the fluctuations in the magnetosphere and inter- planetary space observed by satellites.

Dr Sarabhai's more recent work was connected with an analysis of geomagnetic fluctuations and their interrelation with phenomena occurring in the atmosphere, the ionosphere, the magnetosphere and also in interplanetary space in response to solar activity. He used to say that it was almost possible to throw away the satellites and study what is going on in interplanetary space through an analysis of phenomena on the Earth.

Valuable as Dr Sarabhai's contributions were to the scientific field in which his primary interest lay, he will be remembered in his own country for his continuous involvement in bringing modern science and technology to bear on the important problems of India. Thus as chairman of the AEC he enthusiastically subscribed to and furthered Homi Bhabha's belief that a nuclear power programme would be at least as important for some developing countries as for industrialized countries. He formulated plans for agro-industrial complexes built around large nuclear power plants, which would serve as food factories in addition to providing the power for large industrial enterprises. His interest in space grew naturally out of his preoccupation with natural phenomena in interplanetary space; however, he pushed his plans for communication and television satellites with a missionary zeal because he believed that this would perhaps be the only way in which the half million villages of his country could be knitted together, and effective programmes in family planning, adult education and agricultural reform launched.

$\mathrm{He}$ had a special aptitude for handling men and organizations. In the traditional structure of India he emphasized the importance of the managerial role of scientific and technical men for converting responsibilities for mere control into functions requiring innovation and achievement. Thus alongside his scientific and technological activities he had time and energy to help set up the Ahmedabad Textile Industries Research Association and the Indian Institute of Management and a Community Science Centre at Ahmedabad. Dr Sarabhai's humanistic interests led him to an active participation in the Pugwash Movement and in large scale problems of disarmament and of development. 
In his style of working, hurry had a charming leisurely quality about it, even though every minute of his time was claimed by one or the other of his selfcreated projects. Within the space of an hour he could go from cosmic-ray modulation, to rocket propellants at Thumba, to power reactors at $\mathrm{Kal}$ pakam, to the television satellite experiment, to community science education, to antenna systems for communication links, to infrared devices for surveillance of crop disease, to the administrative details of setting up a new public corporation and back perhaps to cosmic rays. And each of these transitions was deep, involving decision making, unwasteful of words, and outwardly done with a naturalness and charm which always overwhelmed his friends.

Vikram Sarabhai will be missed on the Indian scene, as a scientist, as a scientific visionary, as a doer of things and as a remarkable human being.

\section{Sir Charles Harington}

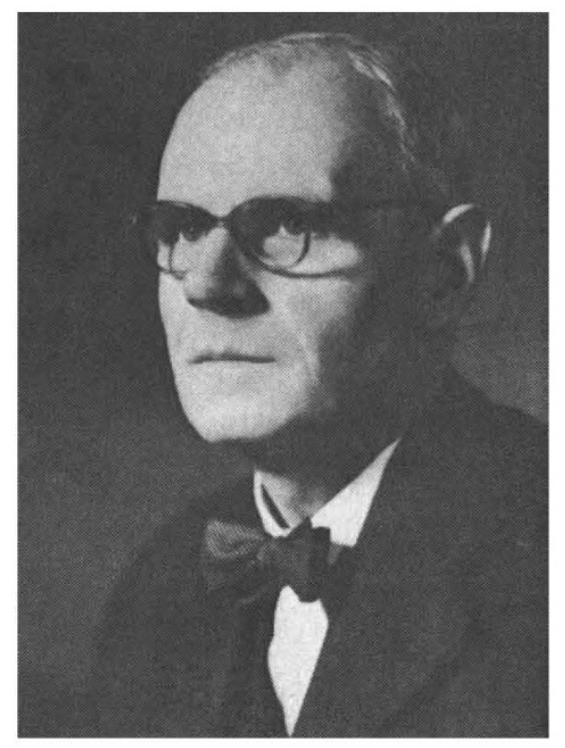

WrTH the death of Sir Charles Harington on February 4, Britain lost not only an outstanding biochemist who was one of the leading figures in the field between the two wars, but also a distinguished administrator of medical research.

Charles Robert Harington was born in 1897 in that part of Herefordshire which is close to the Welsh border. His father was a parson with strong scholarly leanings and his general family background was that of law and the army rather than of science. From Malvern College he went to Cambridge where he read chemistry. A physical disability prevented Harington from joining one of the services in the first war and he was thus able to complete his degree. From Cambridge he went to Edinburgh to work under Barger, who exerted a profound influence on his scientific development. For the rest of his life Harington became identified with biological and particularly medical research, and his knowledge of medicine and his special understanding of clinical problems dated largely from his early experience in Edinburgh. After a short stay in the United States, where he worked with H. D. Dakin and D. D. Van Slyke, he went to University College Hospital Medical School in London, where he spent twenty happy years. In 1942 he was appointed director of the National Institute for Medical Research which, at the time of his appointment, was situated at Mount Vernon, Hampstead. The staff of the institute at that time was relatively small and a large part of the work which went on was either directly or indirectly connected with the war effort. At the end of the war some new appointments to the scientific staff were made, but no great expansion was possible until, in 1949, the institute was moved to its present site in Mill Hill. Harington was mainly responsible for the considerable development of the National Institute which took place at that time.

The appointment of Harington, a non-medical man, as director of the National Institute for Medical Research was somewhat unexpected, but he fully justified the confidence which the Medical Research Council placed in him. One of his outstanding characteristics was the unfailing support and wise counsel which he gave to promising young research workers. There are many people who now occupy important positions in biomedical research in Britain who owe their success to a large extent to the help Harington gave them early in their careers. $\mathrm{He}$ also considered it important to establish close contact between the different divisions and so any attempt to overemphasize departmental boundaries was resisted. This planned cooperation between different disciplines, he considered, was one of the major differences between a national institute and the set-up of ordinary university departments. On the other hand, Harington was careful not to interfere with the scientific freedom of his staff, and this was so marked that it was sometimes difficult to obtain any advice from him on scientific matters. Harington felt that a research institute provided the opportunity for gifted people to concentrate on research and be free from major administrative responsibilities. It was for this reason that he found it difficult to delegate managerial responsibility to a significant extent, even to his senior colleagues. Harington managed to attract many outstanding workers to the National Institute and he maintained the standard of excellence which was set up in the first place, for a much smaller institute, by Sir Henry Dale.

The scientific work for which Harington will best be remembered is that which he published in 1926 and 1927 on the chemistry of thyroxine. $\mathrm{He}$ established the structure of this hormone and together with Barger described its synthesis. Two years later he succeeded in resolving thyroxine and he also characterized other iodine-containing compounds of the thyroid gland. It is perhaps difficult nowadays to appreciate fully the excitement which was caused among British biochemists when Harington first announced the structure of thyroxine at a meeting of the Biochemical Society in 1926.

In 1935 he synthesized glutathione, which at that time was an impressive achievement. A few years later Harington started a series of investigations in the field of synthetic immunochemistry, in which specific antibodies were used to examine certain metabolic processes. He was, for instance, able to suppress the action of thyroxine in rats by prior treatment with anti-thyroxyl thyroglobulin serum. This work, which involved the preparation of well-defined derivatives of proteins, was interrupted by the Second World War. Harington also worked on insulin, on the synthesis of peptides and various other topics. Techniques he used were largely those of the classical organic chemist, but his general outlook was that of a biologist. After the Second World War, Harington started experimental work again in the laboratory, but because of his heavy administrative duties he found it difficult to acquire the new techniques which were being introduced at that time. He preferred to work mainly with his own hands and never aspired to leading a large team.

Harington had a profound influence on a large number of medical scientists and biochemists, and was greatly respected in the scientific world generally. $\mathrm{He}$ was possessed of an unusually marked sense of duty and he was a man of considerable loyalty and deep affection, which he was very shy to display. He was a member of the Medical Research Council, a member of the Agricultural Research Council, an honorary secretary of the Biochemical Society and editor of the Biochemical Journal for about 12 years. Among the many honours he received was the KBE in 1962, the Royal Medal of the Royal Society in 1944 and the Gold Medal of the Society of Apothecaries in 1953. What he valued more than any honours which were bestowed on him, however, was the affection and respect which he received from almost everyone who was closely associated with him. 